\title{
Molecular evidence to support a proposal to reserve the designation Mycobacterium avium subsp. avium for bird-type isolates and 'M. avium subsp. hominissuis' for the human/porcine type of $M$. avium
}

\footnotetext{
${ }^{1}$ Innogenetics N.V., Industriepark Zwijnaarde 7, PO Box 4, B-9052, Ghent, Belgium

2 Diagnostic Laboratory for Infectious Diseases and Perinatal Screening, National Institute of Public Health and the Environment (RIVM), PO Box 1, 3720 BA Bilthoven, The Netherlands

${ }^{3}$ Department of Microbiology, Institute of Tropical Medicine (ITM), Nationalestraat 155, B-2000, Antwerp, Belgium
}

\author{
Wouter Mijs, ${ }^{1}$ Petra de Haas, ${ }^{2}$ Rudi Rossau, ${ }^{1}$ Tridia Van Der Laan, ${ }^{2}$ \\ Leen Rigouts, ${ }^{3}$ Françoise Portaels ${ }^{3}$ and Dick van Soolingen ${ }^{2}$
} Author for correspondence: Dick van Soolingen. Tel: +3130 2742363. Fax: + 31302744418.
e-mail: d.van.soolingen@ rivm.nl

\begin{abstract}
In an attempt to clarify the taxonomy of the Mycobacterium avium complex, the relationship between IS1245 RFLP, growth temperature, 16S rDNA signature sequences and the 16S-23S rDNA internally transcribed spacer (ITS) of $160 \mathrm{M}$. avium-complex isolates from different sources was investigated. All 70 isolates identified as $M$. avium by INNO-LiPA MycOBACTERIA (Innogenetics, Belgium), a DNA probe test that targets the ITS, and by 16S rDNA analysis carried multiple copies of IS1245. Three isolates with multiple copies of IS1245 were identified by 165 rDNA analysis as Mycobacterium intracellulare and by LiPA as $M$. intracellulare $(n=1)$ and $M$. avium-intracellulare complex $(n=2)$. A dichotomy among the $M$. avium isolates was found on the basis of a $C$ and a $G$ signature nucleotide at position 228 of the 16S-23S rDNA spacer sequence, and this grouping was largely confirmed on the basis of similarities in IS1245 RFLPs. Strains with the characteristic three-band IS1245 'bird-type', as well as $M$. avium subsp. silvaticum or 'wood-pigeon' strains, invariably contained the C signature. A third characteristic that separated the $M$. avium bird-type isolates from $M$. avium isolates from humans and other mammals was growthtemperature tolerance: in contrast to bird isolates, human/porcine isolates grew at 24 and $45^{\circ} \mathrm{C}$. Based on differences in IS1245 RFLP, 16S-23S rDNA ITS and growth temperature, $M$. avium isolates originating from birds should be considered as a separate, evolutionarily conserved taxon. Because all $M$. avium isolates from birds are invariably of this type, the designation $M$. avium subsp. avium should be reserved for these bird-type strains. For clarity in the epidemiology of $M$. avium-related disease, isolates from humans and pigs with multibanded IS1245 RFLPs merit a separate designation. The designation ' $M$. avium subsp. hominissuis' is suggested for this group of bacteria.
\end{abstract}

Keywords: Mycobacterium avium complex, IS1245 RFLP, 16S-23S rRNA spacer, LiPA

\section{INTRODUCTION}

Although bacteria of the Mycobacterium avium com-

Abbreviations: ITS, internally transcribed spacer; LiPA, line probe assay; MAC, Mycobacterium avium complex.

The GenBank accession numbers for the 16S-23S rDNA spacer nucleotide sequences determined in this work are AF315826 (Mac-J), AF315827 (MacK), AF315828 (Mac-L), AF315829 (Mac-M), AF315830 (Mac-N), AF315831 (Mac-O), AF315832 (Mac-P), AF315833 (Mac-Q), AF315834 (Mac-R), AF315835 (Mac-S), AF315836 (Mac-T), AF315837 (Mac-U), AF315838 (MavF) and AF315839 (Mav-G). plex (MAC) cause a variety of diseases including tuberculosis-like disease in humans and birds, disseminated infections in AIDS patients and otherwise immunocompromised patients, lymphadenitis in humans and mammals and paratuberculosis (Johne's disease) in ruminants, they are ubiquitous in soil and water (Horsburgh, 1991; Inderlied et al., 1993; Portaels, 1995; Von Reyn et al., 1993). The MAC contains at least two clearly defined species: $M$. avium and Mycobacterium intracellulare. However, a significant proportion of the strains in this complex cannot 
be classified in either species (Frothingham \& Wilson, 1994; Wayne et al., 1993).

Serotyping divides the MAC into 28 serovars. Reference strains with serovars $1-6,8-11,21$ and 28 are considered to represent $M$. avium, while those with serovars 7, 12-20 and 25 are assigned to $M$. intracellulare (Saito et al., 1990; Wayne et al., 1993). However, up to a third of all isolates cannot be serotyped (Böddinghaus et al., 1990). Based on biochemical and DNA analysis, $M$. avium can be further subdivided into subspecies corresponding to pathogenicity and host-range characteristics: $M$. avium subsp. avium, M. avium subsp. silvaticum and $M$. avium subsp. paratuberculosis (Thorel et al., 1990). RFLP typing with the insertion sequences IS900 (Green et al., 1989), IS901 (Kunze et al., 1991) and IS1245 (Guerrero et al., 1995) as probes can be used as markers for further subdivision among M. avium strains. IS900 is present specifically in $M$. avium subsp. paratuberculosis. The presence of IS901, as well as a specific three-banded IS1245 RFLP pattern, correlates well with the bird type of M. avium (Komijn et al., 1999; Kunze et al., 1991; Ritacco et al., 1998; Van Soolingen et al., 1998).

The 16S rDNA sequence is considered as the molecular 'gold standard' for mycobacterial species identification; a highly polymorphic region has been shown to contain species-specific DNA polymorphisms (Böddinghaus et al., 1990; Kirschner et al., 1993a). However, other semi-conserved genes, like hsp65 (Devallois et al., 1997; Leão et al., 1999; Swanson et al., 1997; Telenti et al., 1993) and rрoB (Kim et al., 2001), and the 16S-23S rDNA internally transcribed spacer (ITS) region (Abed et al., 1995; Barry et al., 1991; Glennon et al., 1994; Portaels et al., 1996; Roth et al., 1998) have been shown to be more discriminating. The $16 \mathrm{~S}-23 \mathrm{~S}$ rDNA ITS sequence can be used to distinguish between the species $M$. avium and $M$. intracellulare. Furthermore, extended ITS sequence information has indicated that the MAC is genetically very heterogeneous. Also, among strains within the species M. avium and M. intracellulare, minor $16 \mathrm{~S}-23 \mathrm{~S}$ rDNA spacer sequence variation has been observed (De Smet et al., 1995; Frothingham \& Wilson, 1993, 1994; Roth et al., 2000). The MAC can thus be subdivided into sequevars on the basis of differences in the 16S-23S rDNA ITS. However, the correlation of this observation with other genetic or phenotypic methods of grouping MAC isolates is unknown. To date, this technique has only been applied to reference strains and clinical isolates of human origin (De Smet et al., 1995; Frothingham \& Wilson, 1993, 1994).

Therefore, in this study, the concordance of several approaches to the grouping of MAC isolates originating from different sources was investigated. IS 1245 RFLP typing, phenotypic characteristics, DNA sequence analysis of the 16S rDNA and the 16S-23S rDNA ITS region, AccuProbe (Gen-Probe) and the reverse hybridization line probe assay (LiPA) were included to gain insights into the taxonomic grouping of MAC isolates from several hosts.

\section{METHODS}

Bacterial strains. A total of 160 mycobacterial isolates identified as belonging to the MAC on phenotypic grounds or by using the MAC AccuProbe (Gen-Probe) were investigated in this study. The sources and countries of origin of all isolates are summarized in Table 1. It should be noted that these isolates were selected on the basis of the sources of isolation, the presence/absence of IS1245 DNA and the IS1245-associated DNA polymorphism (Beggs et al., 2000; Komijn et al., 1999; Ritacco et al., 1998; Schneider, 1998). Although MAC isolates with bird-type IS1245 RFLP patterns were almost invariably isolated from birds, we deliberately included bird-type isolates from other sources in this study (Komijn et al., 1999; Ritacco et al., 1998; Schneider, 1998). The MAC isolates from Belgium, India, Zaire (now the Democratic Republic of Congo), Italy, Australia, Benin and Finland were retrieved from the strain collection of the Mycobacteria Department of the Institute of Tropical Medicine (ITM) in Antwerp, Belgium. The isolates from The Netherlands, Argentina and Zambia originated from the strain collection of the Mycobacteria Department at the National Institute of Public Health and the Environment (RIVM) in Bilthoven, The Netherlands. The cultures from the USA were kindly provided by Dr M. L. Beggs (University of Arkansas for Medical Sciences, Little Rock, AR, USA); Dr J. Falkinham (Virginia Polytechnic Institute and State University, VA, USA) provided the cigarette isolates. One of the most significant and comprehensive studies on the taxonomy of MAC bacteria was conducted by the International Working Group on Mycobacterial Taxonomy (IWGMT). Therefore, strains IWGMT 17 and IWGMT 26 were included in this study.

Phenotypic identification. Identification on the basis of biochemical tests and growth characteristics was performed as described previously (Komijn et al., 1999; Thorel et al., 1990).

Preparation of samples. Strains were kept at $-70{ }^{\circ} \mathrm{C}$ prior to testing. For identification procedures, cells were taken from the freezer and grown on Löwenstein-Jensen medium with (RIVM) or without (ITM) pyruvate. Cell suspensions were made in $100 \mu \mathrm{l}$ Milli-Q water (Sigma-Aldrich) by taking a small loopful of bacteria either from the Löwenstein-Jensen slant or from an aliquot of the $-70^{\circ} \mathrm{C}$ collection of bacterial isolates. The cells were inactivated at $95^{\circ} \mathrm{C}$ for $10 \mathrm{~min}$ and spun down at $10000 \mathrm{~g}$ for $1 \mathrm{~min}$. Aliquots of the supernatant were used as targets for the tests.

DNA fingerprinting. DNA fingerprinting of MAC isolates was performed by RFLP typing using the insertion sequence IS 1245 as a probe as described previously (Van Soolingen et al., 1998). To facilitate computer-assisted analysis, internal and external molecular size markers and high-resolution gels $(24 \mathrm{~cm})$ were used as described in a proposal for standardization of IS1245 RFLP typing (Van Soolingen et al., 1998). Computer-assisted analysis of the IS1245 fingerprints was carried out by using the BIONUMERICS software version 4.0 (Applied Maths). The RFLP patterns were compared by using the unweighted pair group method with arithmetic averages (UPGMA) clustering method and by using the Dice coefficient according to the instructions of the manufacturer of BIONUMERICS. 
Table 1. Isolates and strains investigated

\begin{tabular}{|c|c|c|c|c|}
\hline RIVM no. & IS1245 type & LiPA result & Origin & Country of origin \\
\hline 9800845 & Bird type & M. avium $\mathrm{C}$ & Bird, wood pigeon & Belgium \\
\hline 9800846 & Bird type & M. avium $\mathrm{C}$ & Bird, duck & Belgium \\
\hline 9800847 & Bird type & M. avium $\mathrm{C}$ & Bird, goose & Belgium \\
\hline 9800850 & Bird type & M. avium $\mathrm{C}$ & Bird, goose & Belgium \\
\hline 37229 & Bird type & M. avium $\mathrm{C}$ & Bird, gull & Netherlands \\
\hline $160-74$ & Bird type & M. avium $\mathrm{C}$ & Bird, goose & Netherlands \\
\hline $75 / 219$ & Bird type & M. avium $\mathrm{C}$ & Bird, turkey & Netherlands \\
\hline D61958 & Bird type & M. avium $\mathrm{C}$ & Bird, fieldfare & Netherlands \\
\hline D71076 & Bird type & M. avium $\mathrm{C}$ & Bird, owl & Netherlands \\
\hline 16186 & Bird type & M. avium $\mathrm{C}$ & Human & Netherlands \\
\hline 17689 & Bird type & M. avium $\mathrm{C}$ & Human & Netherlands \\
\hline 9501279 & Bird type & M. avium $\mathrm{C}$ & Mammal, pig & Argentina \\
\hline 9800849 & Bird type & M. avium $\mathrm{C}$ & Mammal, cat & Belgium \\
\hline 9800854 & Bird type & M. avium $\mathrm{C}$ & Mammal, cow & Belgium \\
\hline 9800855 & Bird type & M. avium $\mathrm{C}$ & Mammal, cow & Belgium \\
\hline V11 & Bird type & M. avium $\mathrm{C}$ & Mammal, pig & Netherlands \\
\hline IWGMT 17 & Bird type & M. avium $\mathrm{C}$ & Reference & Netherlands \\
\hline IWGMT 26 & Bird type & M. avium $\mathrm{C}$ & Reference & Netherlands \\
\hline 9501268 & Type 2 & M. avium $\mathrm{C}$ & Human & Argentina \\
\hline 9601550 & Type 2 & M. avium $\mathrm{C}$ & Human & Netherlands \\
\hline 9601596 & Type 2 & M. avium $\mathrm{C}$ & Human & Netherlands \\
\hline 9602129 & Type 2 & M. avium $\mathrm{C}$ & Human & Netherlands \\
\hline 9701619 & Type 3 & M. avium $\mathrm{T}$ & Human & Netherlands \\
\hline 9600861 & Type 4 & M. avium $\mathrm{C}$ & Human & Netherlands \\
\hline $2000-00325$ & Type 5 & M. avium $\mathrm{C}$ & Human & USA \\
\hline $2000-00337$ & Type 5 & M. avium $\mathrm{C}$ & Human & USA \\
\hline 9601288 & Type 6 & M. avium $\mathrm{C}$ & Human & Netherlands \\
\hline $2000-00333$ & Type 6 & M. avium $\mathrm{T}$ & Human & USA \\
\hline 9800858 & Type 7 & M. avium $\mathrm{C}$ & Mammal, pig & Belgium \\
\hline 9800851 & Silvaticum type & M. avium $\mathrm{C}$ & Bird, penguin & Belgium \\
\hline 9801574 & Silvaticum type & M. avium $\mathrm{C}$ & Bird, wood pigeon & Belgium \\
\hline 9801017 & Cigarette type & M. avium $\mathrm{C}$ & Cigarettes & USA \\
\hline 9801024 & Cigarette type & M. avium $\mathrm{C}$ & Cigarettes & USA \\
\hline 2000-00332 & Positive & M. avium $\mathrm{C}$ & Human & USA \\
\hline 9800912 & Positive & M. avium $\mathrm{G}$ & Environment, unknown & Finland \\
\hline 9800913 & Positive & M. avium $\mathrm{G}$ & Environment, unknown & Finland \\
\hline 9800916 & Positive & M. avium $\mathrm{G}$ & Environment, unknown & Finland \\
\hline 9800917 & Positive & M. avium $\mathrm{G}$ & Environment, unknown & Finland \\
\hline 9800918 & Positive & M. avium $\mathrm{G}$ & Environment, unknown & Finland \\
\hline 9600008 & Positive & M. avium $\mathrm{G}$ & Human & Netherlands \\
\hline 9600670 & Positive & M. avium $\mathrm{G}$ & Human & Netherlands \\
\hline 9601238 & Positive & M. avium $\mathrm{G}$ & Human & Netherlands \\
\hline 9601246 & Positive & M. avium $\mathrm{G}$ & Human & Netherlands \\
\hline 9601651 & Positive & M. avium $\mathrm{G}$ & Human & Netherlands \\
\hline 9601815 & Positive & M. avium $\mathrm{G}$ & Human & Netherlands \\
\hline 9601995 & Positive & M. avium $\mathrm{G}$ & Human & Netherlands \\
\hline 9900525 & Positive & M. avium $\mathrm{G}$ & Human & Netherlands \\
\hline 9900536 & Positive & M. avium $\mathrm{G}$ & Human & Netherlands \\
\hline 9900537 & Positive & M. avium $\mathrm{G}$ & Human & Netherlands \\
\hline 9900538 & Positive & M. avium $\mathrm{G}$ & Human & Netherlands \\
\hline $2000-00326$ & Positive & M. avium $\mathrm{G}$ & Human & USA \\
\hline $2000-00327$ & Positive & M. avium $\mathrm{G}$ & Human & USA \\
\hline $2000-00328$ & Positive & M. avium $\mathrm{G}$ & Human & USA \\
\hline $2000-00329$ & Positive & M. avium $\mathrm{G}$ & Human & USA \\
\hline
\end{tabular}


Table 1 (cont.)

\begin{tabular}{|c|c|c|c|c|}
\hline RIVM no. & IS1245 type & LiPA result & Origin & Country of origin \\
\hline $2000-00330$ & Positive & M. avium $\mathrm{G}$ & Human & USA \\
\hline $2000-00331$ & Positive & M. avium $\mathrm{G}$ & Human & USA \\
\hline 9800852 & Positive & M. avium $\mathrm{G}$ & Mammal, cow & Belgium \\
\hline 9800853 & Positive & M. avium $\mathrm{G}$ & Mammal, cow & Belgium \\
\hline 9800848 & Positive & M. avium $\mathrm{G}$ & Mammal, dog & Belgium \\
\hline 9800856 & Positive & M. avium $\mathrm{G}$ & Mammal, pig & Belgium \\
\hline 9800857 & Positive & M. avium $\mathrm{G}$ & Mammal, pig & Belgium \\
\hline 9800859 & Positive & M. avium $\mathrm{G}$ & Mammal, pig & Belgium \\
\hline 9800860 & Positive & M. avium $\mathrm{G}$ & Mammal, pig & Belgium \\
\hline 9800861 & Positive & M. avium $\mathrm{G}$ & Mammal, pig & Belgium \\
\hline 9800862 & Positive & M. avium $\mathrm{G}$ & Mammal, pig & Belgium \\
\hline 9700615 & Positive & M. avium $\mathrm{G}$ & Mammal, pig & Netherlands \\
\hline 9700622 & Positive & M. avium $\mathrm{G}$ & Mammal, pig & Netherlands \\
\hline 9700657 & Positive & M. avium $\mathrm{G}$ & Mammal, pig & Netherlands \\
\hline 9700662 & Positive & M. avium $\mathrm{G}$ & Mammal, pig & Netherlands \\
\hline 9700672 & Positive & M. avium $\mathrm{G}$ & Mammal, pig & Netherlands \\
\hline $2000-00334$ & Positive & M. intracellulare & Human & USA \\
\hline $2000-00335$ & Positive & MIC 2 & Human & USA \\
\hline $2000-00336$ & Positive & MIC 2 & Human & USA \\
\hline 9800903 & Negative & M. intracellulare & Environment, soil & Italy \\
\hline 9600022 & Negative & M. intracellulare & Human & Netherlands \\
\hline 9600424 & Negative & M. intracellulare & Human & Netherlands \\
\hline 9600477 & Negative & M. intracellulare & Human & Netherlands \\
\hline 9600486 & Negative & M. intracellulare & Human & Netherlands \\
\hline 9600851 & Negative & M. intracellulare & Human & Netherlands \\
\hline 9600866 & Negative & M. intracellulare & Human & Netherlands \\
\hline 9600871 & Negative & M. intracellulare & Human & Netherlands \\
\hline 9600927 & Negative & M. intracellulare & Human & Netherlands \\
\hline 9600929 & Negative & M. intracellulare & Human & Netherlands \\
\hline 9601067 & Negative & M. intracellulare & Human & Netherlands \\
\hline 9601081 & Negative & M. intracellulare & Human & Netherlands \\
\hline 9601103 & Negative & M. intracellulare & Human & Netherlands \\
\hline 9601276 & Negative & M. intracellulare & Human & Netherlands \\
\hline 9601510 & Negative & M. intracellulare & Human & Netherlands \\
\hline 9601517 & Negative & M. intracellulare & Human & Netherlands \\
\hline 9601795 & Negative & M. intracellulare & Human & Netherlands \\
\hline 9701639 & Negative & M. intracellulare & Human & Netherlands \\
\hline 9600592 & Negative & M. simiae & Human & Netherlands \\
\hline 9601643 & Negative & Mycobacterium sp. & Human & Netherlands \\
\hline 9700610 & Negative & M. xenopi & Mammal, pig & Netherlands \\
\hline 9800920 & Negative & MIC 1.1.b & Environment, soil & Benin \\
\hline 9601431 & Negative & MIC 1.1.b & Human & Netherlands \\
\hline 9801875 & Negative & MIC 1.1.b & Human & Netherlands \\
\hline 9701602 & Negative & MIC 1.1.b & Human & Netherlands \\
\hline 9900293 & Negative & MIC 1.1.b & Human & Zambia \\
\hline 9800911 & Negative & MIC 1.2 & Environment, dust & India \\
\hline 9800906 & Negative & MIC 1.2 & Environment, soil & Italy \\
\hline 9600270 & Negative & MIC 1.2 & Human & Netherlands \\
\hline 9600439 & Negative & MIC 1.2 & Human & Netherlands \\
\hline 9600515 & Negative & MIC 1.2 & Human & Netherlands \\
\hline 9601388 & Negative & MIC 1.2 & Human & Netherlands \\
\hline 9601800 & Negative & MIC 1.2 & Human & Netherlands \\
\hline 9801682 & Negative & MIC 1.2 & Human & Netherlands \\
\hline 9801789 & Negative & MIC 1.2 & Human & Netherlands \\
\hline
\end{tabular}


Table 1 (cont.)

\begin{tabular}{|c|c|c|c|c|}
\hline RIVM no. & IS1245 type & LiPA result & Origin & Country of origin \\
\hline 9801833 & Negative & MIC 1.2 & Human & Netherlands \\
\hline 9900523 & Negative & MIC 1.2 & Human & Netherlands \\
\hline 9900810 & Negative & MIC 1.2 & Human & Netherlands \\
\hline 9800907 & Negative & MIC 2 & Environment, soil & Italy \\
\hline 9800908 & Negative & MIC 2 & Environment, soil & Italy \\
\hline 9600263 & Negative & MIC 2 & Human & Netherlands \\
\hline 9600468 & Negative & MIC 2 & Human & Netherlands \\
\hline 9600516 & Negative & MIC 2 & Human & Netherlands \\
\hline 9600548 & Negative & MIC 2 & Human & Netherlands \\
\hline 9600577 & Negative & MIC 2 & Human & Netherlands \\
\hline 9601127 & Negative & MIC 2 & Human & Netherlands \\
\hline 9601698 & Negative & MIC 2 & Human & Netherlands \\
\hline 9801790 & Negative & MIC 2 & Human & Netherlands \\
\hline 9602094 & Negative & MIC 2 & Human & Netherlands \\
\hline 9900022 & Negative & MIC 2 & Human & Netherlands \\
\hline 9900051 & Negative & MIC 2 & Human & Netherlands \\
\hline 9900146 & Negative & MIC 2 & Human & Netherlands \\
\hline 9900327 & Negative & MIC 2 & Human & Netherlands \\
\hline 9900344 & Negative & MIC 2 & Human & Netherlands \\
\hline 9900431 & Negative & MIC 2 & Human & Netherlands \\
\hline 9900438 & Negative & MIC 2 & Human & Netherlands \\
\hline 9900579 & Negative & MIC 2 & Human & Netherlands \\
\hline 9800897 & Negative & MIC 3.1 & Environment, unknown & Zaire \\
\hline 9600870 & Negative & MIC 3.1 & Human & Netherlands \\
\hline 9701604 & Negative & MIC 3.1 & Human & Netherlands \\
\hline 9701646 & Negative & MIC 3.1 & Human & Netherlands \\
\hline 9900005 & Negative & MIC 3.1 & Human & Netherlands \\
\hline 9800899 & Negative & MIC 3.2 & Environment, soil & Italy \\
\hline 9800902 & Negative & MIC 3.2 & Environment, soil & Italy \\
\hline 9601616 & Negative & MIC 3.2 & Human & Netherlands \\
\hline 9601940 & Negative & MIC 3.2 & Human & Netherlands \\
\hline 9800909 & Negative & MIC 3.3 & Environment, soil & Australia \\
\hline 9800898 & Negative & MIC 3.3 & Environment, plant & Zaire \\
\hline 9601404 & Negative & MIC 3.3 & Human & Netherlands \\
\hline 9601918 & Negative & MIC 3.3 & Human & Netherlands \\
\hline 9701605 & Negative & MIC 3.3 & Human & Netherlands \\
\hline 9900288 & Negative & MIC 3.3 & Human & Zambia \\
\hline 9800900 & Negative & MIC 3.4 & Environment, soil & Italy \\
\hline 9800905 & Negative & MIC 3.4 & Environment, soil & Italy \\
\hline 9801669 & Negative & MIC 3.4 & Human & Netherlands \\
\hline 9802080 & Negative & MIC 3.4 & Human & Netherlands \\
\hline 9600055 & Negative & MIC 3.5 & Human & Netherlands \\
\hline 9601002 & Negative & MIC 3.5 & Human & Netherlands \\
\hline 9800921 & Negative & MIC 4 & Environment, tap water & Belgium \\
\hline 9800914 & Negative & MIC 4 & Environment, unknown & Finland \\
\hline 9800915 & Negative & MIC 4 & Environment, unknown & Finland \\
\hline 9800919 & Negative & MIC 4 & Environment, unknown & Finland \\
\hline 9800910 & Negative & MIC 4 & Environment, water & India \\
\hline 9800901 & Negative & MIC 4 & Environment, soil & Italy \\
\hline 9800904 & Negative & MIC 4 & Environment, soil & Italy \\
\hline 9600915 & Negative & MIC 4 & Human & Netherlands \\
\hline 9801560 & Negative & MIC 4 & Human & Netherlands \\
\hline
\end{tabular}


16S rDNA analysis. Amplification of $700 \mathrm{bp}$ of the $16 \mathrm{~S}$ rDNA was performed using $15 \mathrm{pmol} 16 \mathrm{~S}-8 \mathrm{~F}$ primer $\left(5^{\prime}\right.$ AGAGTTTGATCMTGGYTCAG $\left.3^{\prime}\right)$ and $10 \mathrm{pmol}$ of the mycobacteria-specific primer 16S-M259 (5' TTTCACGAACAACGAGACAA 3') (Kirschner et al., 1993b). The primers and $3 \mu \mathrm{l}$ supernatant of the heat-inactivated suspension were added to a Ready-To-Go PCR bead (Amersham Pharmacia) and the reaction volume was adjusted to $25 \mu \mathrm{l}$ using Milli-Q water (Sigma-Aldrich). The amplification mixtures were subjected to an initial denaturation of $3 \mathrm{~min}$ at $94^{\circ} \mathrm{C}$ and 35 cycles of $94{ }^{\circ} \mathrm{C}$ for $20 \mathrm{~s}, 55^{\circ} \mathrm{C}$ for $1 \mathrm{~min}$ and $72^{\circ} \mathrm{C}$ for $1 \mathrm{~min}$ followed by a final extension period of $72{ }^{\circ} \mathrm{C}$ for $6 \mathrm{~min}$. Amplified PCR products, expected to be of $700 \mathrm{bp}$, were analysed by $2 \%$ agarose gel electrophoresis and purified by using the PCR purification kit of Qiagen. The nucleotide sequence of this part of the $16 \mathrm{~S}$ rDNA was determined on the forward strand by direct sequencing of the PCR product on an automated capillary DNA sequencer (model 310; Applied Biosystems), using fluorescence-labelled dideoxynucleotide terminators (ABI PRISM BigDye Terminator cycle sequencing ready reaction kit; Applied Biosystems). Analysis of the forwardstrand sequence data was done using DNASTAR 5.0 software (DNAstar). The species-specific (region A) and genusspecific (region B) portions of the $16 \mathrm{~S}$ rDNA were analysed as described by Kirschner et al. (1993b). The 16S rDNA was compared with the known sequences described by Kirschner et al. (1993b) and with the BLAST database of the National Center for Biotechnology Information.

AccuProbe tests. AccuProbe tests (Gen-Probe) for the MAC and for $M$. avium and $M$. intracellulare separately were performed according to the instructions of the manufacturer.

Temperature growth range. A set of 30 MAC isolates selected on the basis of differences in IS1245 RFLP patterns, comprising seven bird-type strains, four multibanded strains, one type-2 strain, two cigarette isolates and 16 IS1245-negative isolates, were tested for their temperature ranges for growth. The isolates were grown at temperatures of $24,30,35,37,39,42$ and $45^{\circ} \mathrm{C}$ on solid LöwensteinJensen medium supplemented with pyruvate. Growth was interpreted after 28 days.

LiPA. The LiPA is based on the reverse hybridization principle (Stuyver et al., 1993). Specific oligonucleotides are immobilized as lines at known locations on a membrane strip and hybridized with a biotin-labelled PCR product. The hybrids formed are subsequently detected colorimetrically by adding a conjugate (alkaline phosphataselabelled streptavidin) followed by a substrate (5-bromo-4chloro-3-indolylphosphate and nitroblue tetrazolium). Probes were designed to hybridize in a hybridization solution of $3 \times \mathrm{SSC}$ and $0 \cdot 2 \% \mathrm{SDS}$, at a hybridization temperature of $62{ }^{\circ} \mathrm{C}$. In this study, three different strips were used, all based on the $16 \mathrm{~S}-23 \mathrm{~S}$ rDNA ITS as the target for amplification and detection.

First, strip 1 (INNO-LiPA MYCOBACTERIA; Innogenetics) was used to test all isolates. This test carries 14 probe lines. Twelve probe lines react specifically with Mycobacterium tuberculosis (MTB), Mycobacterium kansasii (MKA), Mycobacterium xenopi (MXE), Mycobacterium gordonae (MGO), M. avium (MAV), M. intracellulare (MIN), Mycobacterium scrofulaceum (MSC) and the Mycobacterium chelonaeMycobacterium abscessus complex $(\mathrm{MCH})$. For both $M$. kansasii and the $M$. chelonae-M. abscessus complex, three probe lines each are included on the strips to distinguish between environmental and possible clinically significant isolates. Two probe lines consist of general probes: one is termed 'MYC' for the genus Mycobacterium and one, termed 'MAIS', reacts with all MAC isolates, including $M$. avium, $M$. intracellulare and $M$. scrofulaceum. Furthermore, Mycobacterium malmoense and some Mycobacterium haemophilum isolates also react with this probe.

A second LiPA (strip 2) was used to differentiate isolates that reacted positively with the MAIS probe, but negatively with the specific $M$. avium, $M$. intracellulare or $M$. scrofulaceum probes on the INNO-LiPA MYCOBACTERIA strip. Eleven probe lines are present on strip 2: the Mycobacterium genus probe, specific probes for $M$. malmoense and $M$. haemophilum (since these particular species react with the MAIS probe on strip 1) and eight probes that generate specific probe patterns for different subgroups of MAC (see Fig. 2).

Finally, a third LiPA (strip 3), containing two probes and the Mycobacterium genus probe, was used to screen for the signature sequences at position 228 of the $16 \mathrm{~S}-23 \mathrm{~S}$ rDNA spacer region of $M$. avium. One probe was specific for $\mathrm{C}$ at this position; the other was specific for $G$ (see Fig. 3).

Amplification was performed as follows: $1 \mu \mathrm{l}$ of the supernatant of the heat-inactivated suspension was used as the target for the PCR, which was performed in a final volume of $50 \mu \mathrm{l}$ containing $50 \mathrm{mM} \mathrm{KCl}, 10 \mathrm{mM}$ Tris $/ \mathrm{HCl}(\mathrm{pH} \mathrm{8.3})$, $1.5 \mathrm{mM} \mathrm{MgCl}_{2}, 200 \mathrm{mM}$ each dNTP and 1.5 U AmpliTaq polymerase (Perkin Elmer). The primers (P1 and P2), used at 50 pmol each per reaction, were biotinylated at their $5^{\prime}$ ends. In the GeneAmp PCR System 9700 (Perkin Elmer), the following cycling protocol was applied: initial denaturation at $95^{\circ} \mathrm{C}$ for $1 \mathrm{~min}$ and 40 cycles consisting of $30 \mathrm{~s}$ at $95^{\circ} \mathrm{C}$, $30 \mathrm{~s}$ at $62^{\circ} \mathrm{C}$ and $30 \mathrm{~s}$ at $72{ }^{\circ} \mathrm{C}$, followed by immediate cooling to $4^{\circ} \mathrm{C}$. The mean length of the amplicon for MAC strains is $410 \mathrm{bp}$. This amplicon was used as the target for all three LiPA strips. For all three LiPAs, hybridization was performed according to the instructions of the INNO-LiPA MYCOBACTERIA kit.

ITS nucleotide sequencing. The nucleotide sequence of the 16S-23S rDNA ITS was determined on both strands by direct sequencing of the PCR product on an automated DNA sequencer (model 377; Applied Biosystems) using fluorescence-labelled dideoxynucleotide terminators (ABI PRISM BigDye Terminator cycle sequencing ready reaction kit; Applied Biosystems). The PCR was performed using primer P1, with the M13 (UP-21) universal primer site synthesized at its $5^{\prime}$ end, and primer P2. Amplicons were purified by using the PCR purification kit of Qiagen. Sequencing reactions were performed with the universal M13 (UP-21) primer and P2. The new ITS sequences were aligned with those available in the databases (GenBank, National Center for Biotechnology Information) and further processed with GENEBASE version 1.0 (Applied Maths). Ambiguities in published databases were considered as identities.

\section{RESULTS}

\section{IS1245 RFLP typing}

All 70 mycobacterial isolates from six different sources (Table 2) identified as $M$. avium on the basis of $16 \mathrm{~S}$ rDNA sequence analysis and the INNO-LiPA MYCOBACTERIA test contained IS1245 DNA as shown in 
Table 2. Source, specification and geographical origin of selected isolates based on IS1245 RFLP type, LiPA strip results and temperature range for growth

LiPA strip test results are indicated as follows. Strip 1: 1, MAIS; 2, M. avium; 3, M. intracellulare; 4, M. xenopi; 5 ,

Mycobacterium sp. Strip 2: 1, MIC 1.1.b; 2, MIC 1.2; 3, MIC 2; 4, MIC 3.1; 5, MIC 3.2; 6, MIC 3.3; 7, MIC 3.4; 8, MIC 3.5; 9 , MIC 4, Strip 3: 1, M. avium C; 2, M. avium G; 3, M. avium T. The number of isolates/strains tested for their growth temperature range is indicated.

\begin{tabular}{|c|c|c|c|c|c|c|c|c|c|c|c|c|c|c|c|c|c|c|c|c|c|c|c|c|}
\hline \multirow[t]{2}{*}{ Specification* } & \multirow[t]{2}{*}{ IS 1245 type } & \multicolumn{5}{|c|}{ LiPA strip 1} & \multicolumn{9}{|c|}{ LiPA strip 2} & \multicolumn{3}{|c|}{ LiPA strip 3} & \multicolumn{6}{|c|}{ Growth temperature $\left({ }^{\circ} \mathrm{C}\right)$} \\
\hline & & 1 & 2 & 3 & 4 & 5 & 1 & 2 & 3 & 4 & 5 & 6 & 7 & 8 & 9 & 1 & 2 & 3 & $n$ & 24 & $30-37$ & 39 & 42 & 45 \\
\hline \multicolumn{25}{|l|}{ Mammal } \\
\hline $1 \mathrm{cat}^{1}, 2 \mathrm{cow}^{1}, 2 \mathrm{pig}^{2,3}$ & Bird type & & 5 & & & & & & & & & & & & & 5 & & & 2 & - & + & + & + & - \\
\hline $1 \mathrm{pig}^{1}$ & Type 7 & & 1 & & & & & & & & & & & & & 1 & & & & & & & & \\
\hline $2 \operatorname{cow}^{1}, 11 \operatorname{pig}^{6 \times 1,5 \times 2}, 1 \operatorname{dog}^{1}$ & Multibanded & & 14 & & & & & & & & & & & & & & 14 & & & & & & & \\
\hline $1 \mathrm{pig}^{2}$ & Negative & & & & 1 & & & & & & & & & & & & & & & & & & & \\
\hline \multicolumn{25}{|l|}{ Bird } \\
\hline 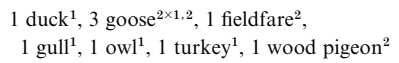 & Bird type & & 9 & & & & & & & & & & & & & 9 & & & 3 & - & + & + & + & - \\
\hline 1 penguin ${ }^{1}, 1$ wood pigeon ${ }^{1}$ & Silvaticum type & & 2 & & & & & & & & & & & & & 2 & & & & & & & & \\
\hline $\begin{array}{l}\text { Cigarettes } \\
2 \text { tobacco }\end{array}$ & \multicolumn{23}{|c|}{ Cigarettes } & + \\
\hline \multicolumn{25}{|l|}{ Environment } \\
\hline 5 unknown ${ }^{9}$ & Multibanded & & 5 & & & & & & & & & & & & & & 5 & & 3 & + & + & + & + & + \\
\hline $\begin{array}{l}1 \text { dust }^{4}, 1 \text { plant }^{5}, 12 \text { soil }^{10 \times 6,1 \times 7,1 \times 8}, \\
2 \text { tap water }^{1,4}, 4 \text { unknown } \times 9,1 \times 5\end{array}$ & Negative & 19 & & 1 & & & 1 & 2 & 2 & 1 & 2 & 2 & 2 & & 7 & & & & & & & & & \\
\hline \multicolumn{25}{|l|}{ Human } \\
\hline 2 patients ${ }^{2}$ & Bird type & & 2 & & & & & & & & & & & & & 2 & & & 2 & - & + & + & + & - \\
\hline 4 patients $^{2}$ & Type 2 & & 4 & & & & & & & & & & & & & 4 & & & 1 & + & + & + & + & + \\
\hline 1 patient ${ }^{2}$ & Type 3 & & 1 & & & & & & & & & & & & & & & 1 & & & & & & \\
\hline 1 patient ${ }^{2}$ & Type 4 & & 1 & & & & & & & & & & & & & 1 & & & & & & & & \\
\hline 2 patients $^{10}$ & Type 5 & & 2 & & & & & & & & & & & & & 2 & & & & & & & & \\
\hline 2 patients $^{2,10}$ & Type 6 & & 2 & & & & & & & & & & & & & 1 & & 1 & & & & & & \\
\hline 21 patients $^{11 \times 2,10 \times 10}$ & Multibanded & 2 & 18 & 1 & & & & & 2 & & & & & & & 1 & 17 & & 1 & + & + & + & + & + \\
\hline 17 patients $^{2}$ & Negative & & & 17 & & & & & & & & & & & & & & & 5 & + & + & + & + & - \\
\hline 49 patients $^{2}$ & Negative & 47 & & & & 2 & 4 & 10 & 17 & 4 & 2 & 4 & 2 & 2 & 2 & & & & 11 & + & + & $+1-$ & - & - \\
\hline Reference & & & & & & & & & & & & & & & & & & & & & & & & \\
\hline IWGMT 17, IWGTM 26 & Bird type & & 2 & & & & & & & & & & & & & 2 & & & & & & & & \\
\hline Totals & & 68 & 70 & 19 & 1 & 2 & 5 & 12 & 21 & 5 & 4 & 6 & 4 & 2 & 9 & 32 & 36 & 2 & 30 & & & & & \\
\hline
\end{tabular}

* Numbers and sources of isolates are indicated. Country of origin is indicated by superscript numbers as: 1, Belgium; 2, The Netherlands; 3, Argentina; 4, India; 5, Zaire; 6, Italy; 7, Australia; 8, Benin; 9, Finland; 10, USA (Little Rock, AR); 11, Zambia; 12, USA (Virginia).

RFLP typing (Fig. 1). In addition, one of 19 isolates identified as $M$. intracellulare on LiPA and two of 68 isolates identified as MAIS on LiPA exhibited multibanded patterns in IS1245-based RFLP typing.

The IS 1245 bird-type patterns, showing three bands, of $8 \cdot 7,3 \cdot 2$ and $2.9 \mathrm{~kb}$ (Bono et al., 1995; Ritacco et al., 1998), were found in two M. avium isolates from cows, two from pigs, one from a cat, nine from different bird species, two from humans and in two reference isolates. The two $M$. avium subsp. silvaticum strains, isolated from a penguin and a wood pigeon, showed only a one-band difference with respect to the IS1245 birdtype pattern, as described previously (Bono et al., 1995). The two $M$. avium isolates from cigarettes contained two and four copies of IS1245, and the respective IS1245 RFLP patterns were not found among strains from other sources. However, the few bands of the cigarette isolates matched with bands of one particular group (type 2) of $M$. avium isolates from humans. Ten $M$. avium strains from humans and one from a pig contained other IS1245 RFLP patterns, named type 2 to type 7. Multibanded and highly polymorphic patterns were encountered for 14 mammal isolates, five environmental isolates and 18 clinical isolates, but not in bird isolates (Fig. 1, Table 2).

The IS1245 RFLP patterns were assembled in two large groupings with only $20 \%$ mutual similarity. All isolates in the first group exhibited multibanded (13-39 copies) IS 1245 RFLP patterns. In the second group, all isolates except one exhibited one to nine copies of IS 1245. The exceptional strain contained 13 copies of the IS1245 element (type 4) (Fig. 1).

\section{INNO-LiPA MYCOBACTERIA (LiPA strip 1)}

For all 160 isolates that were identified as MAC on phenotypic grounds or with the MAC AccuProbe, the spacer region was amplified and analysed by reverse hybridization using the commercial INNO-LiPA MYCOBACTERIA strip. All reacted with the general Mycobacterium probe on the strip. Furthermore, all except 


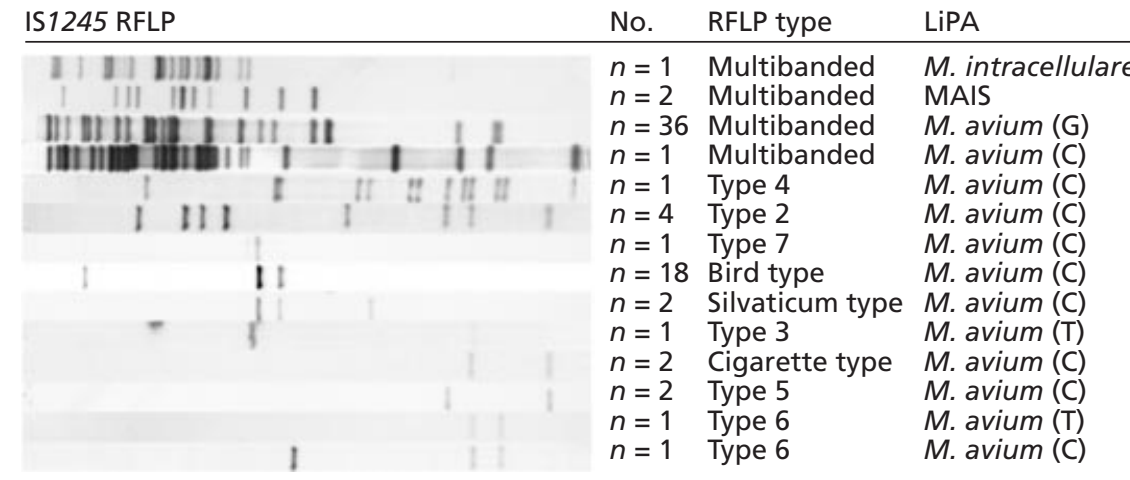

Fig. 1. Representative IS1245 RFLP patterns of the MAC isolates included in this study and their LiPA results.

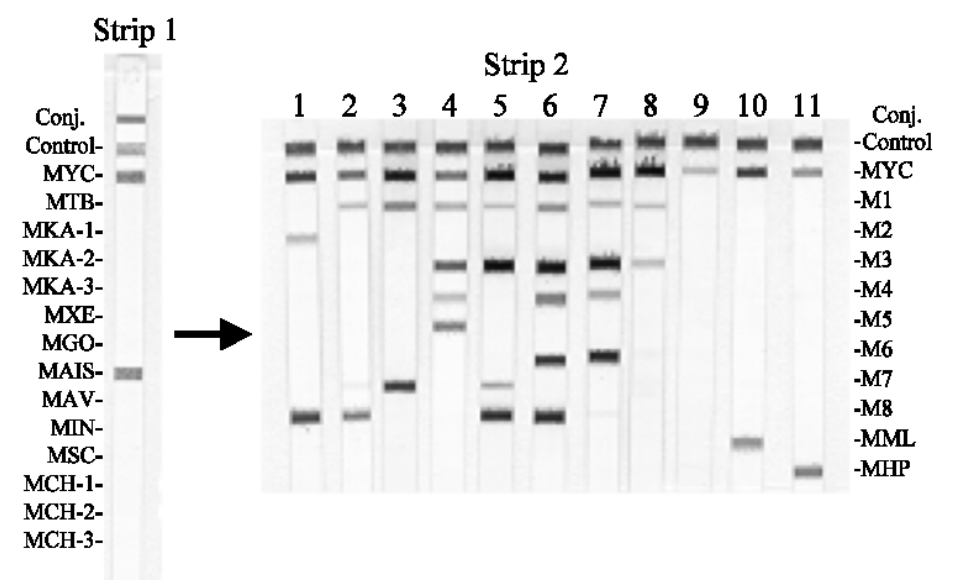

Fig. 2. Representative LiPA patterns on strip 2. Strip 2 allows further differentiation of isolates with an MAIS pattern in the INNOLiPA MYCOBACTERIA test (strip 1 illustrated). Different subgroups can be distinguished: MIC 1.1.b (1), MIC 1.2 (2), MIC 2 (3), MIC 3.1 (4), MIC 3.2 (5), MIC 3.3 (6), MIC 3.4 (7), MIC 3.5 (8) and MIC 4 (9); in addition, two species-specific probes are present, one for $M$. malmoense (10) (probe $\mathrm{MML}$ ) and one for M. haemophilum (11) (probe MHP).

three reacted with the MAIS probe: two isolates reacted only with the general Mycobacterium probe and were therefore classified as unidentified mycobacteria, whereas one isolate reacted with the $M$. xenopi probe on the strip, although the strain had previously been identified phenotypically as MAC (Komijn et al., 1999). Seventy isolates, including two isolates belonging to M. avium subsp. silvaticum, were identified as $M$. avium by LiPA and invariably contained IS1245 DNA. Of the remaining 87 isolates, 19 were identified by LiPA as M. intracellulare and 68 reacted exclusively with the MAIS probe. All these 87 isolates that did not react with the $M$. avium probe were negative in the IS1245 RFLP hybridization, except for three: one was identified by both the AccuProbe and LiPA test as M. intracellulare, and two were $M$. intracellulare AccuProbe-positive and identified by LiPA as MAIS (Table 2).

\section{LiPA strip 2}

The 68 MAC isolates that reacted only with the MAIS probe on the INNO-LiPA MYCOBACTERIA strip were further analysed on strip 2. This research strip was designed to allow further differentiation of MAC isolates (W. Mijs and R. Rossau, unpublished). According to the probe patterns obtained, these 49 clinical and 19 environmental isolates could be subdivided into nine different groups in the MAC (Fig. 2, Tables 1-4).

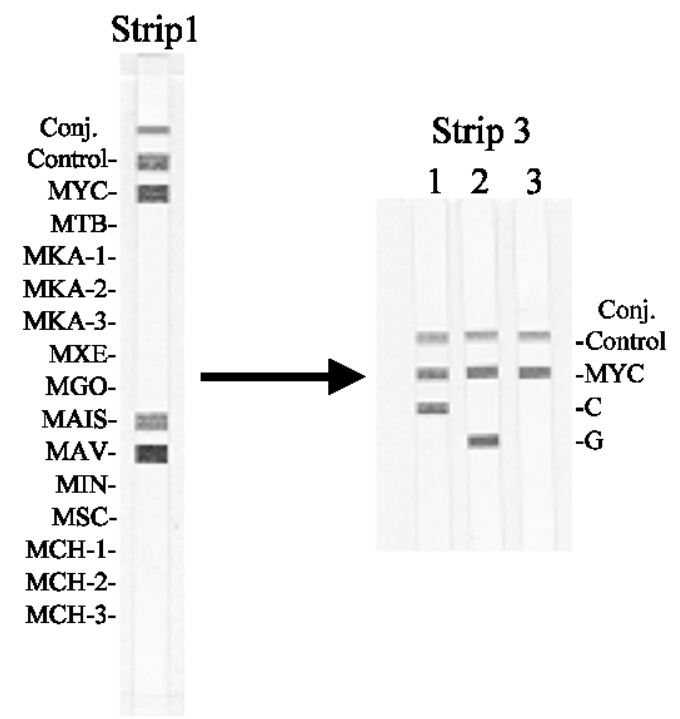

Fig. 3. Representative LiPA patterns on strip 3. Lines $C$ and $G$ detect a single mismatch, $C$ or $G$, respectively, thereby screening for the signature sequence at position 228 in the $M$. avium spacer: $M$. avium 'bird' - C (1), M. avium 'pig' - G (2), M. avium $-\mathrm{T}(3)$ are shown.

\section{LiPA strip 3}

A third LiPA research strip (Fig. 3) was used to enable differentiation of the $70 \mathrm{M}$. avium isolates based on the known polymorphism at position 228 in the spacer 
Table 3. Nucleotide mismatches in the ITS regions of all described and new sequevars of $M$. avium, $M$. intracellulare and the MAC

Nucleotides are indicated relative to the M. intracellulare ITS reference sequence (Min-A, accession no. L07859). Only those positions at which nucleotide changes were observed are listed. Identities are indicated by dots (.); gaps are indicated by dashes (-).

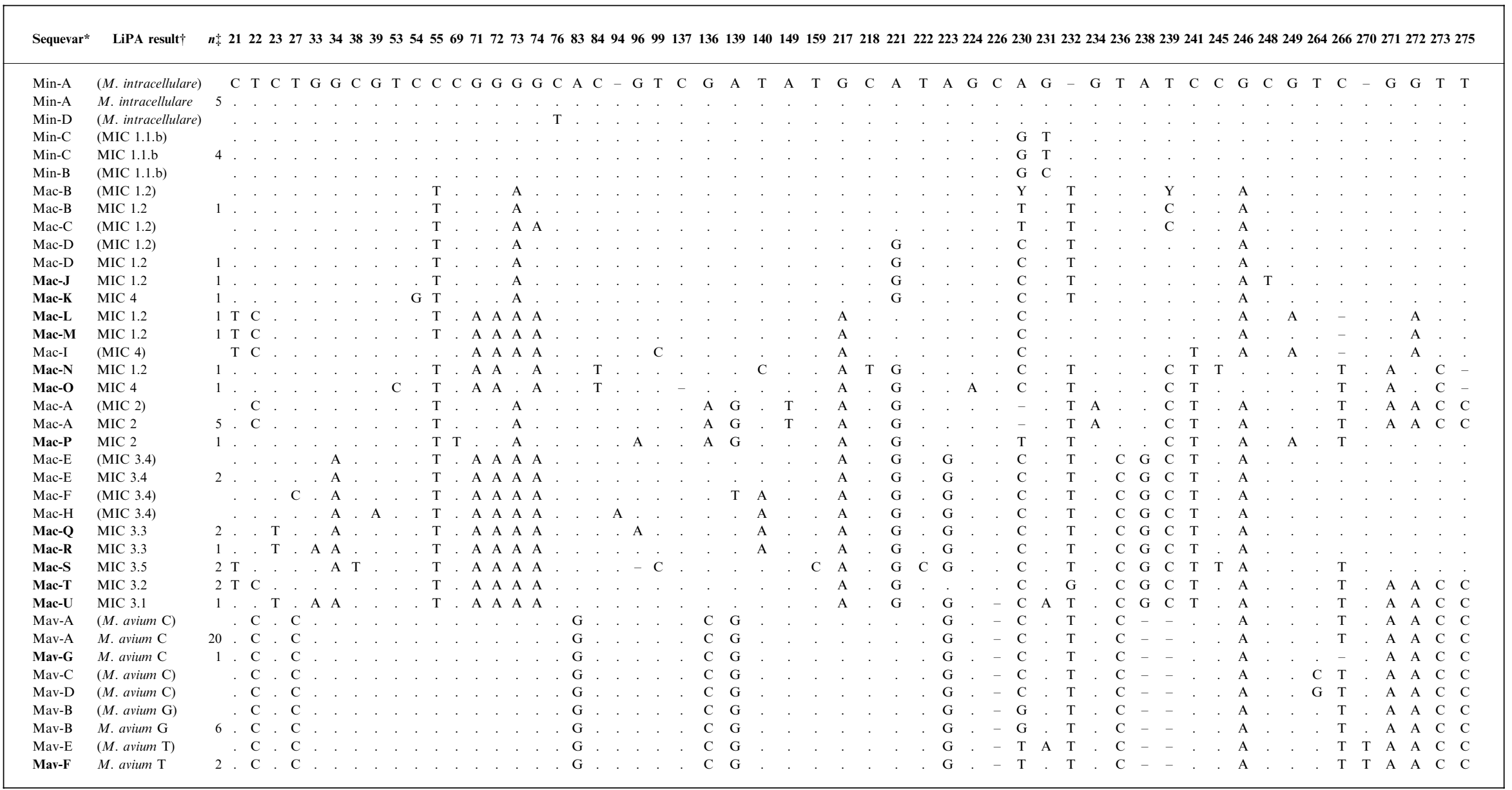

* New sequevars are indicated in bold.

$\dagger$ Theoretically derived LiPA patterns are indicated in parentheses.

$\$$ Number of isolates tested in LiPA. 
Table 4. Relationship between $M$. intracellulare AccuProbe test results, $16 \mathrm{~S}$ rDNA sequencing and analysis of non- $M$. avium MAC isolates

For 16S rDNA region A, types represent: A, M. intracellulare; B, M. intracellulare serovar 18; C, M. intracellulare serovar 7 (according to Kirschner et al., 1993b); D, IWGMT 90242 (according to Wayne et al., 1996); E, identical to type C except for an extra $\mathrm{T}$ at position 219 (type E has not been described previously). For $16 \mathrm{~S}$ rDNA region B, types represent: A, M. avium subsp. avium, M. avium subsp. paratuberculosis, $M$. intracellulare, Mycobacterium szulgai, M. malmoense and Mycobacterium asiaticum; B, Mycobacterium marinum, M. haemophilum, Mycobacterium ulcerans and M. intracellulare (according to Kirschner et al., 1993b); C, IWGMT 90233 according to Wayne et al. (1996).

\begin{tabular}{|c|c|c|c|c|c|c|c|c|c|c|c|c|}
\hline \multirow{2}{*}{$\begin{array}{l}\text { M. intracellulare } \\
\text { AccuProbe test } \\
\text { result }\end{array}$} & \multicolumn{2}{|c|}{ 16S rDNA } & \multicolumn{9}{|c|}{ LiPA test result } & \multirow[t]{2}{*}{ Total } \\
\hline & Region A & Region B & M. intracellulare & MIC 1.1.b & MIC 1.2 & MIC 2 & MIC 3.1 & MIC 3.2 & MIC 3.3 & MIC 3.4 & MIC 4 & \\
\hline \multirow[t]{5}{*}{ Positive } & A & A & 11 & 2 & & & & & & & & 13 \\
\hline & A & B & & & & 18 & & & & & & 18 \\
\hline & B & A & & 1 & & & & & & & & 1 \\
\hline & D & A & & 1 & & & & & & & & 1 \\
\hline & B & в & & & & 1 & & & & & & 1 \\
\hline \multirow[t]{6}{*}{ Negative } & B & A & & & & & 2 & 2 & 1 & & 1 & 6 \\
\hline & B & B & & & 6 & & 1 & & & & & 7 \\
\hline & B & $\mathrm{C}$ & & & 2 & & & & & & & 2 \\
\hline & $\mathrm{C}$ & B & & & & & & & 2 & & & 2 \\
\hline & D & A & & & 1 & & & & & 2 & & 3 \\
\hline & E & A & & & & & & & & & 1 & 1 \\
\hline Totals & & & 11 & 4 & 9 & 19 & 3 & 2 & 3 & 2 & 2 & 55 \\
\hline
\end{tabular}

sequence (either $\mathrm{C}$ or $\mathrm{G}$ ), previously described respectively as sequevars Mav-A and Mav-B (Frothingham \& Wilson, 1993). The distinction into two groups on the basis of the similarities in IS 1245 RFLP patterns was almost invariably confirmed by the presence of either $\mathrm{C}$ or $\mathrm{G}$ at position 228 in the spacer sequence. Thirty-six $M$. avium isolates with multibanded and polymorphic IS 1245 patterns reacted with the $\mathrm{G}$ probe, whereas $31 \mathrm{M}$. avium isolates of the second group reacted with the $\mathrm{C}$ probe, indicating the presence of $\mathrm{G}$ or $\mathrm{C}$, respectively, at position 228 in the spacer sequence (Table 2). One exceptional M. avium isolate with a multibanded IS1245 RFLP pattern reacted repeatedly with the $\mathrm{C}$ probe. Two patient isolates, respectively with one and two copies of IS 1245 , did not react with the G or C probe.

\section{S-23S rDNA spacer sequences}

To validate the LiPA results further, the ITS regions from 64 of the 160 Mycobacterium isolates were sequenced. For one of the two isolates that reacted only with the general Mycobacterium probe, a mycobacterial spacer was found that did not match any described or published sequence. For the other isolate, a Mycobacterium simiae spacer sequence was found. Five $M$. intracellulare isolates showed identical spacer sequences, previously named Min-A (Frothingham \& Wilson, 1993). Of the $29 \mathrm{M}$. avium isolates sequenced, 20 had $\mathrm{C}$ at position 228 (Mav-A) and six had $\mathrm{G}$ at this position (Mav-B), in accordance with the LiPA research strip 3 analysis. Two isolates that did not react with the $C$ and $G$ probe on the LiPA research strip 3 had $T$ at this position as well as $T_{7}$ rather than $T_{6}$ at positions 260-266. The latter signature sequence was described earlier for sequevar Mav-E (De Smet et al., 1995). However, our two M. avium T isolates differed from the Mav-E sequevar at position 229, and were therefore termed Mav-F. Furthermore, one of the $M$. avium $\mathrm{C}$ isolates differed from the Mav-A sequevar by having $T_{5}$ at positions 260-266; consequently, it was named sequevar Mav-G. These two new $M$. avium sequevars (Mav-F, Mav-G) were deposited in the GenBank database under accession numbers AF315838 and AF315839. Of the remaining 28 MAC isolates that reacted only with the MAIS probe on strip 1,13 matched a sequence described in the literature [Min-C $(n=4)$, Mac-A $(n=5)$, Mac-B $(n=1)$, Mac$\mathrm{D}(n=1)$, Mac-E $(n=2)]$ and 15 isolates could be divided into 12 different new sequevars (Mac-J to Mac-U, AF315826-AF315837). Observed mismatches between the various MAC spacer sequences and the $M$. intracellulare reference sequence (Min-A; GenBank accession no. L07859) are summarized in Table 3 .

\section{Detailed analysis of non-M. avium MAC isolates}

Fifty-five of the 68 MAIS isolates identified by means of the INNO-LiPA MYCOBACTERIA strips (Table 2) were subjected to the $M$. intracellulare AccuProbe test and $16 \mathrm{~S}$ rDNA sequence analysis (Table 4). The $M$. intracellulare AccuProbe-positive isolates were identified by LiPA as $M$. intracellulare $(n=11)$, MIC 1.1.b $(n=4)$ or MIC $2(n=19)$. All isolates having other MIC ITS types $(n=21)$ did not react with the $M$. intracellulare AccuProbe test. For clarity, the different DNA sequences in the 16S rDNA species- and genusspecific regions are indicated by letter combinations (explained in the legend to Table 4). All 11 isolates identified by INNO-LiPA as $M$. intracellulare, as well as two MIC 1.1.b isolates, revealed the combination $\mathrm{A}-\mathrm{A}$. The combination $\mathrm{A}-\mathrm{B}$ was found exclusively in the 19 isolates that were identified by LiPA as MIC 2, with one exception. This exceptional strain showed the newly described ITS sequevar Mac-P. None of the $M$. 
intracellulare AccuProbe-negative isolates had a species-specific region of type A.

\section{Temperature growth range}

A selection of $30 \mathrm{MAC}$ isolates was tested for their temperature growth range at seven temperatures ranging from 24 to $45^{\circ} \mathrm{C}$. The bird-type isolates did not grow at temperatures of 24 or $45^{\circ} \mathrm{C}$. The multicopy strains, type 2 , and the cigarette-type strains were able to grow over the entire temperature range of $24-45^{\circ} \mathrm{C}$. The IS1245-negative isolates could be divided into two groups based on temperature growth range: one was unable to grow at $45^{\circ} \mathrm{C}$ and another was unable to grow at 42 or $45^{\circ} \mathrm{C}$. These groups were identified by INNO-LiPA MYCOBACTERIA as $M$. intracellulare and MAIS, respectively.

\section{DISCUSSION}

Previous attempts to classify organisms of the MAC have only highlighted the vast heterogeneity within this group. In the present study, we combined several previously described approaches and compared these with new molecular assays such as the reverse line-blot hybridization used in the LiPA system.

Previous studies showed that the IS 1245 insertion element is specific for M. avium. In this study, all $70 M$. avium isolates identified by phenotypic testing and analysis of the 16S rDNA and the ITS carried the IS 1245 insertion element. All of the M. avium isolates reported by Beggs et al. (2000) as lacking IS1245 DNA that were retested in our laboratory appeared to hybridize with the IS 1245 probe (P. de Haas, D. van Soolingen and W. Mijs, unpublished data). However, three isolates that were negative with the $M$. avium probe on the INNO-LiPA MYCOBACTERIA strip harboured multiple copies of IS1245, and were respectively identified as $M$. intracellulare and MAIS by LiPA and as M. intracellulare by the AccuProbe test.

Both the phenotypic and the genetic information presented here reveals that $M$. avium isolates from birds constitute a separate taxon within the MAC. In an earlier study, we found that both the IS901 and IS 1245 RFLPs of bird isolates are highly conserved (Ritacco et al., 1998): all 29 M. avium isolates from 23 different bird species invariably belonged to the birdtype RFLP grouping within the complex, while this type of strain was hardly found in other reservoirs. In a population-based study in The Netherlands in 1997, none of the $195 \mathrm{M}$. avium isolates examined from humans was of the bird type (Schneider, 1998).

In this study, additional reasons are provided to support a separate designation for $M$. avium isolates from birds. Firstly, isolates originating from pigs and humans still grow at $45^{\circ} \mathrm{C}$ while bird types fail to grow at this temperature. Secondly, a signature nucleotide C was found at position 228 of the 16S-23S rDNA ITS region for all $M$. avium isolates that had a characteristic three-banded IS1245 RFLP pattern. M. avium subsp. silvaticum, the 'wood-pigeon' variant of $M$. avium, is closely related to the 'bird-type' strains on the basis of IS1245 RFLP, and also contains the same $\mathrm{C}$ signature nucleotide. In contrast, a $\mathrm{G}$ signature nucleotide was found for isolates that harboured highly polymorphic and multibanded IS1245 RFLP patterns, with only one exception, an isolate that had a multibanded IS1245 RFLP pattern while harbouring a C signature sequence.

Frothingham \& Wilson $(1994,1993)$ as well as De Smet et al. (1995) respectively found previously that $3 / 11$ and $2 / 25$ human clinical isolates harboured a signature nucleotide $\mathrm{C}$ (which they termed sequevar Mav-A) and that respectively $8 / 11$ and $22 / 25$ human isolates had $\mathrm{G}$ (which they termed sequevar Mav-B). Also, as described by De Smet et al. (1995), 1/25 human isolates had $\mathrm{T}$ at this signature position, as well as $T_{7}$ rather than $T_{6}$ at positions $260-266$, which was termed Mav-E. In our study, 11/30 human clinical isolates harboured a signature nucleotide $\mathrm{C}, 17 / 30 \mathrm{had}$ $\mathrm{G}$ and 2/30 had $\mathrm{T}$.

The development of a LiPA (strip 3) based on the position 228 signature nucleotide indicates that it is possible to screen for different subtypes of $M$. avium with this methodology. Indeed, the actual source of $M$. avium infections in humans and pigs remains unclear. The differences between isolates from birds and humans presented here and previously (Komijn et al., 1999; Ritacco et al., 1998) should eliminate the misconceptions about birds being the source of $M$. avium infections in humans. In the epidemiology of $M$. avium-related infection, there is considerable confusion regarding the origin of such infections. To clarify the epidemiology of $M$. avium-related infections, we therefore propose to reserve the designation $M$. avium subsp. avium for the genetically highly conserved, bird-type isolates. These isolates are characterized by a specific IS 1245 RFLP consisting of three bands, of $8 \cdot 7,3 \cdot 2$ and $2 \cdot 9 \mathrm{~kb}$. The $16 \mathrm{~S}-23 \mathrm{~S}$ rDNA spacer region contains the specific $\mathrm{C}$ signature sequence, and these bird types do not grow at temperatures of 24 or $45^{\circ} \mathrm{C}$. Furthermore, M. avium subsp. avium isolates exhibit a highly conserved IS 901 RFLP containing 7-11 copies (Ritacco et al., 1998) and they invariably belong to serovars 1,2 and 3 (Ritacco et al., 1998). M. avium subsp. silvaticum is highly related to $M$. avium subsp. avium and has been isolated mainly from wood pigeons. These strains exhibit a shift of one band in the IS 1245 RFLP pattern, of 8.7 to $2.2 \mathrm{~kb}$, in comparison with the $M$. avium subsp. avium IS1245 RFLP pattern. Furthermore, $M$. avium subsp. silvaticum strains have a conserved IS901 RFLP pattern similar to that of $M$. avium subsp. avium. In contrast to $M$. avium subsp. avium, M. avium subsp. silvaticum strains are mycobactin-dependent (Bono et al., 1995).

If another designation were to be chosen for the $M$. avium strains with multibanded IS1245 RFLP patterns found in humans and pigs (Kirschner et al., 1993a), it would become clear to clinicians that $M$. avium 
infections in humans in most cases do not originate from birds. Because the source of M. avium infections in humans and pigs is unclear at the moment, we propose the designation ' $M$. avium subsp. hominissuis' for this group of $M$. avium bacteria in the complex. This designation should be used for $M$. avium isolates that do not exhibit the specific characteristics of the bird-type isolates. ' $M$. avium subsp. hominissuis' isolates are genetically much more divergent than $M$. avium subsp. avium isolates: most (but not all) $M$. avium isolates from humans and pigs contain multiple copies of IS1245 (Ritacco et al., 1998) and the associated RFLP is highly polymorphic, the $16 \mathrm{~S}-23 \mathrm{~S}$ rDNA spacer region contains the specific $G$ signature sequence and these pig/human isolates grow over the complete temperature range of $24-45^{\circ} \mathrm{C}$. Furthermore, IS 901 has been found only incidentally in ' $M$. avium subsp. hominissuis' isolates and was, in that case, not associated with the characteristic IS901 RFLP found in M. avium subsp. avium (Ritacco et al., 1998).

The IS1245-negative isolates were further analysed with LiPA, with AccuProbe and by sequencing of $16 \mathrm{~S}$ rDNA signature sequences and the ITS. Although the isolates were identified as being MAC, based on morphology and biochemical testing, two isolates turned out to be 'Mycobacterium sp.' and one was identified as $M$. xenopi by the INNO-LiPA MYCOBACTERIA test. For the Mycobacterium sp. isolates, ITS sequencing revealed an $M$. simiae spacer and an 'undefined' Mycobacterium spacer, proving that these isolates are not MAC. Similar anomalies have been noted before (De Smet et al., 1995, 1996), highlighting the limitations of biochemical testing and showing the advantage of DNA-based tests such as LiPA for identification.

All 'true' MAC isolates, including $M$. avium and $M$. intracellulare, reacted with the MAIS probe in the LiPA test. However, two isolates that harboured identical spacer sequences (designated MIC.3.5) gave a very weak reaction with this probe. Sequencing of the spacer region showed them to be identical, showing at least six mismatches with any other spacer sequence. The presence of nucleotide mismatches in the probe region of the MAIS probe explained the weak reaction. Among the MAIS-positives, 19 isolates hybridized with the $M$. intracellulare-specific MIN probe on the INNO-LiPA MycobaCTERIA strip. Sequencing of the spacers of five of them confirmed that they harboured $100 \%$-identical spacer sequences, identical to the described sequevar Min-A. This sequevar is considered as 'true' $M$. intracellulare by the INNO-LiPA MYCOBACTERIA test.

The LiPA 'MAIS' isolates (MAIS probe-positive; $M$. avium- and $M$. intracellulare-negative) were further tested with a second strip (strip 2) and divided into 'MIC' groups - referring to ' $M$. intracellulare complex', since MAC strains seem to be more related to $M$. intracellulare $(99 \cdot 3-91 \cdot 1 \%)$ than to $M$. avium (94.3$89 \cdot 4 \%$ ) at the level of the ITS. According to previous studies, three main groups with eight subgroups (named MIC 1.1.b, 1.2, 2, 3.1, 3.2, 3.3, 3.4 and 4) could be defined on the basis of probe patterns (data not shown). Some of them were equivalent to earlier described sequevars. In this study, these probe patterns and one new probe pattern were found (MIC 3.5).

Sequencing of the spacer region shows that M. avium forms a clearly defined species within the MAC group. The remaining MAC isolates, including $M$. intracellulare, form a very heterogeneous group, with at least 30 different sequences currently known to differ from one another by between one and more than 20 nucleotides (this study; W. Mijs, F. Portaels and R. Rossau, unpublished; De Smet et al., 1995; Frothingham \& Wilson, 1993, 1994). Sequencing confirmed all LiPA strip-2 patterns, but the groupings derived from probe patterns did not always correspond with those derived from spacer sequences. For example, one MIC 4 isolate showed $99.6 \%$ similarity to MIC 1.2 isolates, because the one nucleotide mismatch was situated in one probe region. This illustrates that, although the probe patterns can be considered as a type of fingerprint, the LiPA MIC groups do not match their phylogenetic relationship exactly. Fine-tuning of these probes and relating them to clinical relevance may improve these inaccuracies.

Comparison of two signature-sequence regions in the $16 \mathrm{~S} \mathrm{rDNA}$, the AccuProbe results, INNO-LiPA MYCOBACTERIA and the MIC groupings found with the second LiPA strip revealed the following correlations: (i) all isolates positive with the $M$. intracellulare probe on LiPA and all isolates having a MIC 1.1.b or MIC 2 LiPA pattern were positive for the $M$. intracellulare AccuProbe; (ii) all isolates having other MIC patterns reacted only with the AccuProbe for the MAC. These findings may indicate that the INNO-LiPA MYCOBACTERIA strip identifies a cluster too narrow to include all $M$. intracellulare strains. Indeed, sequencing of the spacer region of MIC 1.1.b isolates revealed $99 \cdot 3 \%$ similarity to the reference spacer of $M$. intracellulare, and was previously described as sequevar Min-C. However, sequencing of the spacer region of MIC 2 isolates revealed only $93.2 \%$ similarity to the reference spacer. The latter finding may indicate that the cluster that is now considered as $M$. intracellulare on the basis of AccuProbe tests is too wide. When comparing these results with those of the $16 \mathrm{~S}$ rDNA signature sequencing, it should be noted that, for M. intracellulare isolates, neither the AccuProbe results nor the LiPA results correlate fully with those obtained by $16 \mathrm{~S}$ polymorphic region sequencing. Isolates with the same $16 \mathrm{~S}$ sequence may give different AccuProbe reactivities and may differ on the basis of the ITS sequence and vice versa (Table 3 ).

\section{Conclusion}

The aim of this study was to clarify the taxonomy of the MAC. We found that IS1245 fingerprinting and the use of the INNO-LiPA MYCOBACTERIA strip based 
on the 16S-23S rDNA ITS are useful tools for clarifying the taxonomy of the MAC. Using these techniques, $M$. avium isolates can be distinguished easily from other MAC isolates by the presence of the IS 1245 insertion element, as well as by a positive reaction with the $M$. avium probe on the INNO-LiPA MYCOBACTERIA strip, a commercially available reverse hybridization assay.

Fingerprinting by IS 1245 RFLP and sequencing of the $16 \mathrm{~S}-23 \mathrm{~S}$ rDNA spacer region also revealed a difference between $M$. avium strains isolated from birds and those isolated from pigs. A specific RFLP pattern and spacer sequence were found for bird types, while other patterns or sequences were found for pig types. The use of two spacer probes easily allows screening for this signature sequence. This may help to pinpoint the reservoir of environmental $M$. avium strains that tend to cause infections in both humans and pigs. The genotypic differences between bird isolates and pig/ human isolates were confirmed by phenotypic differences such as growth temperature, leading us to suggest the designation of subspecies $M$. avium subsp. avium and ' $M$. avium subsp. hominissuis', respectively.

Although $M$. avium can be distinguished easily from other MAC isolates, and even be subdivided into different (sub)species, it is still difficult to apply the name $M$. intracellulare to a specific species, since techniques based on different molecular markers generate different results. Further study is therefore required.

\section{ACKNOWLEDGEMENTS}

Karen De Vreese, Andre Van De Voorde and Fred Shapiro are acknowledged for their critical review and editorial contributions and Georges Van Reybroeck is thanked for sequencing of the ITS. MAC isolates from India and Finland were kindly provided to the ITM by Dr C. N. Paramassivan and Dr M. Katila, respectively. We are grateful to Mr Tony Eger of the ID-Lelystad, The Netherlands, for the biochemical characterization of mycobacterial isolates from pigs.

\section{REFERENCES}

Abed, Y., Bollet, C. \& De Micco, P. (1995). Demonstration of Mycobacterium kansasii species heterogeneity by the amplification of the $16 \mathrm{~S}-23 \mathrm{~S}$ spacer region. J Med Microbiol 43, 156-158.

Barry, T., Colleran, G., Glennon, M., Dunican, L. K. \& Gannon, F. (1991). The $16 \mathrm{~S} / 23 \mathrm{~S}$ ribosomal spacer region as a target for DNA probes to identify eubacteria. PCR Methods Appl 1, 51-56.

Beggs, M. L., Stevanova, R. \& Eisenach, K. D. (2000). Species identification of Mycobacterium avium complex isolates by a variety of molecular techniques. J Clin Microbiol 38, 508-512.

Böddinghaus, B., Wolters, J., Heikens, W. \& Böttger, E. C. (1990). Phylogenetic analysis and identification of different serovars of $\mathrm{Myco-}$ bacterium intracellulare at the molecular level. FEMS Microbiol Lett 70, 197-203.

Bono, M., Jemmi, T., Bernasconi, C., Burki, D., Telenti, A. \& Bodmer, T. (1995). Genotypic characterization of Mycobacterium avium strains recovered from animals and their comparison to human strains. Appl Environ Microbiol 61, 371-373.
De Smet, K. A. L., Brown, I. N., Yates, M. \& Ivanyi, J. (1995). Ribosomal internal transcribed spacer sequences are identical among Mycobacterium avium-intracellulare complex isolates from AIDS patients, but vary among isolates from elderly pulmonary disease patients. Microbiology 141, 2739-2747.

De Smet, K. A. L., Hellyer, T. J., Khan, A. W., Brown, I. N. \& Ivanyi, J. (1996). Genetic and serovar typing of clinical isolates of the Mycobacterium avium-intracellulare complex. Tuber Lung Dis 77, 71-76.

Devallois, A., Goh, K. S. \& Rastogi, N. (1997). Rapid identification of mycobacteria to species level by PCR-restriction length polymorphism analysis of the $h s p 65$ gene and proposal of an algorithm to differentiate 34 mycobacterial species. J Clin Microbiol 35, 2969-2973.

Frothingham, R. \& Wilson, K. H. (1993). Sequence-based differentiation of strains in the Mycobacterium avium complex. J Bacteriol 175, 2818-2825.

Frothingham, R. \& Wilson, K. H. (1994). Molecular phylogeny of the Mycobacterium avium complex demonstrates clinically meaningful divisions. J Infect Dis 169, 305-312.

Glennon, M., Smith, T., Cormican, M., Noone, D., Barry, T., Maher, M., Dawson, M., Gilmartin, J. J. \& Gannon, F. (1994). The ribosomal intergenic spacer region: a target for the PCR based diagnosis of tuberculosis. Tuber Lung Dis 75, 353-360.

Green, E. P., Tizard, M. L. V., Moss, M. T., Thompson, J., Winterbourne, D. J., McFadden, J. J. \& Hermon-Taylor, J. (1989). Sequence and characteristics of IS900, an insertion element identified in human Crohn's disease isolate of Mycobacterium paratuberculosis. Nucleic Acids Res 17, 9063-9073.

Guerrero, C., Bernasconi, C., Burki, D., Bodmer, T. \& Telenti, A. (1995). A novel insertion element from Mycobacterium avium, IS1245, is a specific target for analysis of strain relatedness. J Clin Microbiol 33, 304-307.

Horsburgh, C. R., Jr. (1991). Mycobacterium avium complex infection in the acquired immunodeficiency syndrome. $N$ Engl J Med 324, 1332-1338.

Inderlied, C. B., Kemper, C. A. \& Bermudez, L. E. (1993). The Mycobacterium avium complex. Clin Microbiol Rev 6, 266-310.

Kim, B. J., Lee, K. H., Park, B. N., Kim, S. J., Bai, G. H., Kim, S. J. \& Kook, Y. H. (2001). Differentiation of mycobacterial species by PCRrestriction analysis of DNA (342 base pairs) of the RNA polymerase gene (rpoB). J Clin Microbiol 39, 2102-2109.

Kirschner, P. T., Meier, A. \& Böttger, E. C. (1993a). Genotypic identification and detection of mycobacteria: facing novel and uncultured pathogens. In Diagnostic Molecular Microbiology, pp. 173-190. Edited by D. T. Persing, T. D. White, F. C. Tenover \& T. F. Smith. Washington, DC: American Society for Microbiology.

Kirschner, P., Springer, B., Vogel, U., Meier, A., Wrede, A., Kiekenbeck, M., Bange, F. C. \& Böttger, E. C. (1993b). Genotypic identification of mycobacteria by nucleic acid sequence determination: report of a 2-year experience in a clinical laboratory. J Clin Microbiol 31, 2882-2889.

Komijn, R. E., de Haas, P. E. W., Schneider, M. M. E., Eger, T., Nieuwenhuijs, J. H. M., van den Hoek, R. J., Bakker, D., van Zijderveld, F. G. \& van Soolingen, D. (1999). Prevalence of Mycobacterium avium in slaughter pigs in The Netherlands and comparison of IS 1245 restriction fragment length polymorphism patterns of porcine and human isolates. J Clin Microbiol 37, 1254-1259.

Kunze, Z. M., Wall, S., Appelberg, R., Silva, M. T., Portaels, F. \& McFadden, J. J. (1991). IS901, a new member of a widespread class of atypical insertion sequences, is associated with pathogenicity in $\mathrm{Myco-}$ bacterium avium. Mol Microbiol 5, 2265-2272.

Leão, S. C., Briones, M. R. S., Sircili, M. P., Balian, S. C., Mores, N. \& Ferreira-Neto, J. S. (1999). Identification of two novel Mycobacterium avium allelic variants in pig and human isolates from Brazil by PCRrestriction enzyme analysis. J Clin Microbiol 37, 2592-2597.

Portaels, F. (1995). Epidemiology of mycobacterial diseases. Clin Dermatol 13, 207-222.

Portaels, F., De Rijk, P., Jannes, G., Lemans, R., Mijs, W., Rigouts, L. \& Rossau, R. (1996). The 16S-23S rRNA spacer, a useful tool for 
taxonomical and epidemiological studies of the $M$. chelonae complex Tuber Lung Dis 77 (Suppl. 2), 17-18.

Ritacco, V., Kremer, K., van der Laan, T., Pijnenburg, J. E. P., de Haas, P. E. W. \& van Soolingen, D. (1998). Use of IS901 and IS1245 in RFLP typing of Mycobacterium avium complex: relatedness among serovar reference strains, human and animal isolates. Int J Tuberc Lung Dis 2, 242-251.

Roth, A., Fischer, M., Hamid, M. E., Michalke, S., Ludwig, W. \& Mauch, H. (1998). Differentiation of phylogenetically related slowly growing mycobacteria based on 16S-23S rRNA gene internal transcribed spacer sequences. J Clin Microbiol 36, 139-147.

Roth, A., Reischl, U., Streubel, A., Naumann, L., Kroppenstedt, R. M., Habicht, M., Fischer, M. \& Mauch, H. (2000). Novel diagnostic algorithm for identification of mycobacteria using genus-specific amplification of the 16S-23S rRNA gene spacer and restriction endonucleases. J Clin Microbiol 38, 1094-1104.

Saito, H., Tomioka, H., Sato, K., Tasaka, H. \& Dawson, D. J. (1990). Identification of various serovar strains of Mycobacterium avium complex by using DNA probes specific for Mycobacterium avium and Mycobacterium intracellulare. J Clin Microbiol 28, 1694-1697.

Schneider, M. M. E. (1998). Opportunistic infections in HIV-infected patients. PhD Thesis, University of Utrecht, Utrecht, The Netherlands.

Stuyver, L., Rossau, R., Wyseur, A., Duhamel, M., Vanderborght, B., Van Heuverswyn, H. \& Maertens, G. (1993). Typing of hepatitis $\mathrm{C}$ virus isolates and characterization of new subtypes using a line probe assay. J Gen Virol 74, 1093-1102.

Swanson, D. S., Kapur, V., Stockbauer, K., Pan, X., Frothingham, R. \& Musser, J. M. (1997). Subspecific differentiation of Mycobacterium avium complex strains by automated sequencing of a region of the gene (hsp65) encoding a 65-kilodalton heat shock protein. Int $J$ Syst Bacteriol 47, 414-419.

Telenti, A., Marchesi, F., Balz, M., Bally, F., Böttger, E. \& Bodmer, T. (1993). Rapid identification of mycobacteria to the species level by polymerase chain reaction and restriction enzyme analysis. $J$ Clin Microbiol 31, 175-178.

Thorel, M.-F., Krichevsky, M. \& Vincent Lévy-Frébault, V. (1990). Numerical taxonomy of mycobactin-dependent mycobacteria, emended description of Mycobacterium avium, and description of Mycobacterium avium subsp. avium subsp. nov., Mycobacterium avium subsp. paratuberculosis subsp. nov., and Mycobacterium avium subsp. silvaticum subsp. nov. Int J Syst Bacteriol 40, 254-260.

Van Soolingen, D., Bauer, J., Ritacco, V. \& 8 other authors (1998). IS1245 restriction fragment length polymorphism typing of Mycobacterium avium isolates: proposal for standardization. J Clin Microbiol 36, 3051-3054

Von Reyn, C. F., Waddel, R. D., Eaton, T. \& 7 other authors (1993). Isolation of Mycobacterium avium complex from water in the United States, Finland, Zaire, and Kenya. J Clin Microbiol 31, 3227-3230.

Wayne, L. G., Good, R. C., Tsang, A. \& 13 other authors (1993). Serovar determination and molecular taxonomic correlation in $\mathrm{Myco}$ bacterium avium, Mycobacterium intracellulare, and Mycobacterium scrofulaceum: a cooperative study of the International Working Group on Mycobacterial Taxonomy. Int J Syst Bacteriol 43, 482-489.

Wayne, L. G., Good, R. C., Böttger, E. C. \& 19 other authors (1996). Semantide- and chemotaxonomy-based analyses of some problematic phenotypic clusters of slowly growing mycobacteria, a cooperative study of the International Working Group on Mycobacterial Taxonomy. Int J Syst Bacteriol 46, 280-297. 